\title{
Estudo comparativo entre as esferas de silicone gelatinosas e rígidas em cavidade eviscerada de coelho
}

\author{
Comparative study between gelatinous and hard spheres of silicone in rabbit eviscerated scleral cavity
}

Mayumi Shirota Kanamura ${ }^{1}$, Carlos Roberto Padovani ${ }^{2}$, Elenize Jamas Pereira ${ }^{3}$, Maria Jaqueline Mamprim ${ }^{4}$, Silvana Artioli Schellin ${ }^{5}$

\section{RESUMO}

Objetivo: Avaliar e comparar a biocompatibilidade de esferas de silicone gelatinosas e rígidas em cavidades evisceradas de coelhos.

Métodos: Trinta coelhos tiveram o olho direito eviscerado com implantação de esferas de silicone gelatinosas (Grupo I) ou rígidas (Grupo II). Foi realizada avaliação clínica diária, ultrassonografia da cavidade orbitária, análise histológica e morfométrica da pseudocápsula que se formou ao redor dos implantes aos 7, 30 e 90 dias após a cirurgia, com avaliação estatística dos resultados.

Resultados: Houve boa integração das esferas com os tecidos orbitários e semeIhança de resposta tecidual com ambas as esferas. Duas esferas de silicone gelatinosas e uma rígida extruíram. A pseudocápsula que se formou ao redor das esferas gelatinosas foi mais organizada, com espessura e reação inflamatória menores que a observada nas esferas rígidas.

Conclusões: Esferas de silicone gelatinosas e rígidas tiveram boa integração tecidual em cavidades evisceradas de coelhos.

Descritores: Exenteração orbitária; Enucleação ocular; Anoftalmia/cirurgia; Silicone; Biocompatibilidade; Coelhos

\section{ABSTRACT}

Purpose:Toevaluateand to compare the biocompatibility of gelatinous and hard silicone spheres placed into eviscerated scleral cavities of rabbits.

Method: Thirty rabbits underwent right eye evisceration surgery and replacement of orbital volume using gelatinous (Group I) or hard silicone (Group II) spheres. Seven, 30 and 90 days after the surgical procedure, clinical assessment, ultrasound of the orbit, histological and morphometric evaluation of the pseudocapsule were performed. Data was submitted to statistical analysis.

Results: Similarity of tissue response was observed with both materials. Two gelatinous and one hard silicone spheres had extrusion. The pseudocapsule around the gelatinous spheres was better organized, thinner and with less inflammatory reaction.

Conclusions: Both spheres had good integration to the orbital tissue in rabbit eviscerated cavities.

Keywords: Orbit evisceration; Eye enucleation; Anophthalmos/surgery; Silicone; Biocompatibility; Rabbits

\section{INTRODUÇÃO}

As técnicas de enucleação e evisceração geralmente requerem reposição de conteúdo orbitário para minimizar o déficit de volume e, consequentemente, assimetrias e prejuízos estéticos ${ }^{(1-3)}$. Para repor o volume orbitário perdido, podem ser utilizados materiais autólogos, homólogos, heterólogos ou aloplásticos.

Materiais aloplásticos são os mais utilizados, podendo-se implantar esferas confeccionadas com diversas substâncias, como polimetilmetacrilato, silicone, hidroxiapatita sintética, polietileno poroso(4), biovidro e biocerâmica(5).

Todos os implantes aloplásticos que existem atualmente para reconstrução da cavidade anoftálmica são rígidos, assim como a prótese externa. O movimento constante dos músculos extrínsecos e das pálpebras pode fazer com que a prótese externa tenha contatos traumáticos com o implante orbitário, propiciando pontos de fragilidade na porção anterior da conjuntiva e esclera, com desenvolvimento de deiscências e exposição do implante, cujo evento final poderá ser a extrusão do mesmo.

Alguns estudos analisaram implantes de materiais gelatinosos, como o polietileno gel injetado no subcutâneo de cobaias ${ }^{(6,7)}$ e esferas de polietileno gel, colocados em cavidades anoftálmicas de coelhos ${ }^{(4)}$, ambos com boa resposta tecidual.

Implantes não rígidos, feitos de silicone no estado gelatinoso já foram largamente utilizados em outros locais do corpo humano, como os implantes mamários, em mastoplastias de aumento ${ }^{(8)}$.

O estudo se justifica pelo fato de nunca ter sido antes testada a resposta dos tecidos orbitários ao silicone gelatinoso.

Assim, o presente estudo foi desenvolvido com o objetivo de avaliar a biocompatibilidade de esferas de silicone no estado gelatinoso, implantadas em cavidades anoftálmicas de coelhos, comparando-as com esferas rígidas de silicone.
Submetido para publicação: 24 de outubro de 2011

Aceito para publicação: 7 de março de 2012

Trabalho realizado na Faculdade de Medicina de Botucatu, Universidade Estadual Paulista - UNESP, Universidade Estadual Paulista "Júlio de Mesquita Filho" - UNESP - Botucatu (SP), Brasil.

${ }^{1}$ Médica, Curso Bases Gerais da Cirurgia, Faculdade de Medicina de Botucatu, Universidade Estadual Paulista "Júlio de Mesquita Filho" - UNESP - Botucatu (SP), Brasil.

2 Professor, Departamento de Bioestatística, Instituto de Biociências, Universidade Estadual Paulista "Júlio de Mesquita Filho" - UNESP - Botucatu (SP), Brasil.

${ }^{3}$ Bióloga, Departamento de Clínica Médica, Faculdade de Medicina de Botucatu, Universidade Estadual Paulista "Júlio de Mesquita Filho" - UNESP - Botucatu (SP), Brasil.

4 Veterinária, Departamento de Reprodução Animal e Radiologia Veterinária, Faculdade de Medicina Veterinária e Zootecnia, Universidade Estadual Paulista “Júlio de Mesquita Filho" - UNESP - Botucatu (SP), Brasil.

${ }_{5}^{5}$ Professor, Departamento de Oftalmologia, Otorrinolaringologia e Cirurgia de Cabeça e Pescoço, Faculdade de Medicina de Botucatu, Universidade Estadual Paulista "Júlio de Mesquita Filho" UNESP - Botucatu (SP), Brasil.
Financiamento: Não houve financiamento para este trabalho.

Divulgação de potenciais conflitos de interesse: M.S.Kanamura, Não; C.R.Padovani, Não; E.J.Pereira, Não; M.J.Mamprim, Não; S.A.Schellini, Não.

Endereço para correspondência: Mayumi Shirota Kanamura. Departamento de OFT/ORL/CCP - Faculdade de Medicina de Botucatu - UNESP - Botucatu (SP) - 18618-000 - Brasil E-mail: sartioli@fmb.unesp.br 


\section{MÉTODOS}

Trata-se de um estudo experimental, aleatorizado, realizado na Faculdade de Medicina de Botucatu (FMB)-UNESP, utilizando 30 coeIhos, espécie Oryctolagus cuniculus, fornecidos pelo Biotério Central da UNESP. O estudo seguiu os princípios éticos da experimentação animal (COBEA) e foi aprovado pelo Comitê de Ética da FMB.

Os animais foram divididos por sorteio feito utilizando aleatorização por moeda (cara ou coroa), em dois grupos de 15 animais cada. O número de animais foi determinado por cálculo de tamanho amostral. Os animais foram submetidos à evisceração do olho direito (OD), com implantação de esferas de silicone na cavidade escleral. Os animais do Grupo I (GI) receberam esferas contendo gel de silicone e recobertas por uma membrana de silicone de superfície lisa e os do Grupo II (GII), esferas de silicone compostas por elastômero de silicone (Figura 1 - A e B, respectivamente). As esferas apresentavam 10 mm de diâmetro, fabricadas pela SILIMED Indústria e Comércio Ltda., Rio de Janeiro, Brasil e esterilizadas por métodos físicos.

Todos os animais que evoluíram para óbito ou que apresentaram extrusão durante o período de seguimento foram substituídos.

Os procedimentos cirúrgicos foram realizados sob anestesia geral (zolazepam - Zoleti ${ }^{\circledR} 50$ - Virbac do Brasil, SP, associado ao Anasedan ${ }^{\circledR}$ (xilazina, Vetbrands, SP), na dose de $15 \mathrm{mg} / \mathrm{kg}$, endovenoso (veia marginal auricular). O coelho foi posicionado sobre a mesa cirúrgica, em decúbito lateral esquerdo, com o OD voltado para cima. Foi instilado colírio anestésico (Oxinest ${ }^{\circledR}$, Latinofarma, SP) e aplicação peribulbar e subconjuntival de $1,0 \mathrm{ml}$ de cloridrato de lidocaína com epinefrina (Xylestesin ${ }^{\circledR} 2 \%$, Cristália, SP) para complementação da analgesia. Foi realizada antissepsia da região orbitária com polivinilpirrolidona-iodo 1\%, colocação de campo oftalmológico estéril e blefarostato, abertura corneoescleral com bisturi lâmina 11 (Two Arrows, RPC, Shanghai Med SN, China), com complementação da abertura em $360^{\circ}$ com tesoura Westcott, seguida da remoção da córnea. Evisceração
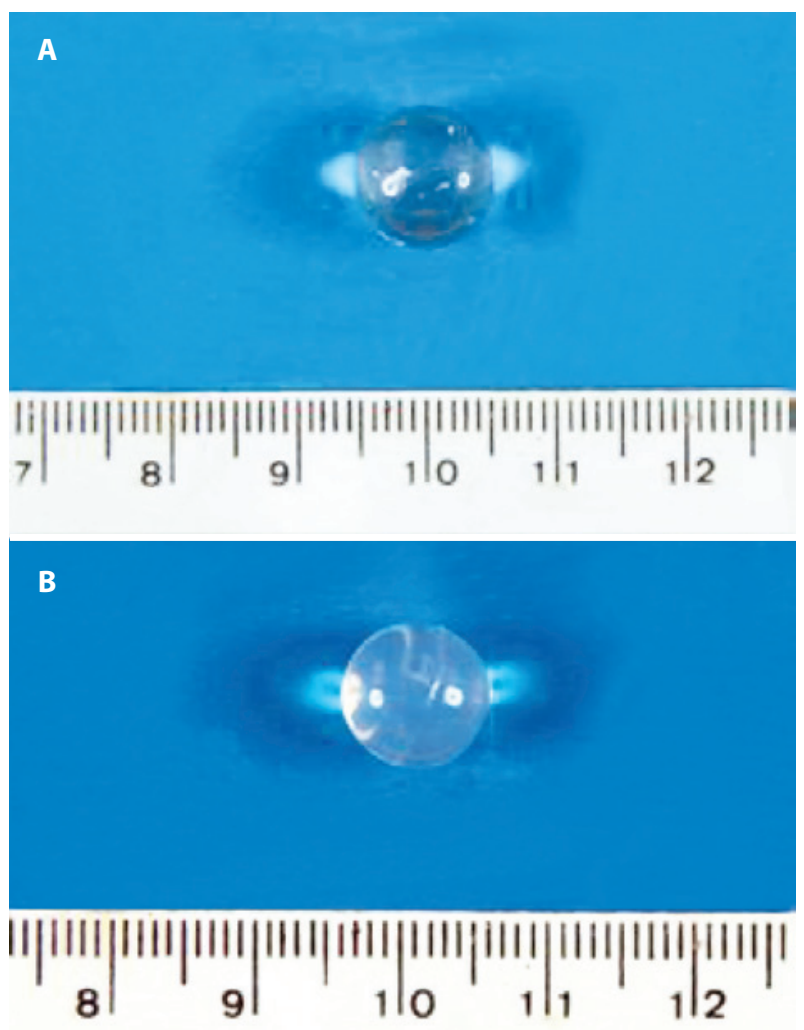

Figura 1. Esferas de silicone gelatinosa (A) e rígida (B) utilizadas no experimento. do conteúdo ocular com cureta, pinça de conjuntiva, espátula, compressas de gaze e cotonetes. Colocação dos implantes de silicone na cavidade escleral, com fechamento da incisão em sutura contínua, com fio inabsorvível trançado 6-0 (Mersilene ${ }^{\circledR}$ 6-0, Ethicon, Johnson \& Johnson, SP), nos planos da esclera e conjuntiva separadamente. Ao final do procedimento, instilação de colírio de ciprofloxacino 0,3\% (Ciloxan ${ }^{\circledR}$, Alcon Laboratórios do Brasil, SP) e antibiótico sistêmico injetável enrofloxacino (Flotril ${ }^{\circledR} 10 \%$, Vitalfarma Ltda, MG), na dose de $0,025 \mathrm{~mL} / \mathrm{kg}$ de peso.

Os animais foram acondicionados em gaiolas individuais, em ambiente com temperatura e iluminação controladas, recebendo ração para a espécie e água ad libitum.

Foram feitas avaliações clínicas diárias, observando alterações sistêmicas ou no sítio operatório. A saúde geral do animal foi estimada pela atividade, apetite e atitude na gaiola; verificação da presença de secreção, deiscência de sutura e presença da esfera na cavidade orbitária. As avaliações foram feitas por uma aluna de iniciação científica que desconhecia a que grupo o animal pertencia.

Cinco animais de cada grupo foram eutanasiados aos 7, 30 e 90 dias após a cirurgia, por dose letal de cloridrato de cetamina 10\% (Cetamin ${ }^{\circledR}$, Rhobifarma Indústria Farmacêutica Ltda, Syntec do Brasil, $P R)$, pela via endovenosa.

Quinze dias depois da cirurgia, animais de ambos os grupos foram submetidos a exame ultrassonográfico da cavidade orbitária, avaliando-se o posicionamento da esfera na órbita, presença de coleção ou processos inflamatórios ao redor ou dentro das esferas.

Após a eutanásia dos animais, as esferas foram retiradas em conjunto com os tecidos orbitários, imersas em formalina 10\% por 48 horas, incluídas em parafina, coradas por hematoxilina e eosina (HE) e avaliadas segundo tipo, localização e intensidade da inflamação nos tecidos ao redor da esfera e sua integração com os tecidos do hospedeiro.

O exame morfométrico foi realizado utilizando microscópio LEICA DM LS com câmara de vídeo acoplada a computador dotado de programa Image Pro-plus (Media Cybernetics, Silver Spring, Maryland, USA) para análise da espessura da pseudocápsula formada ao redor do implante, avaliada nas porções anterior, posterior (coincidindo com a região do polo posterior), superior (fundo-de-saco superior) e inferior (fundo-de-saco inferior), assim como a celularidade da reparação tecidual.

Os dados numéricos foram transferidos para planilha Excel e submetidos à análise estatística, pela técnica de análise de variância multivariada para o modelo de medidas repetidas, no esquema de dois fatores independentes, complementada com o teste de comparações múltiplas de Bonferroni, considerando o nível de significância de $5 \%(P<0,05)^{(9)}$.

\section{RESULTADOS}

Os animais evoluíram bem, alimentando-se normalmente e com atividade normal na gaiola. Foi observada secreção de aspecto mucoide na cavidade anoftálmica, sem sinais de infecção. No Gl ocorreram duas extrusões, uma no 16 ํ e outra no 20 dia de pós-operatório. No Gll ocorreu uma extrusão no 12 ㅇa de pós-operatório e um animal morreu no 5 dia após a cirurgia, não tendo sido identificada a causa do óbito.

\section{Avaliação ULtrassonográfica}

Feita nos animais de 30 e 90 dias. A ultrassonografia não diferenciou os grupos e mostrou o posicionamento das esferas na órbita, presença de pequena quantidade de líquido ao redor da esfera, espessamento de tecido na superfície anterior do implante e, algumas vezes, ecogenicidade no interior da esfera.

\section{Avaliação histológica}

1. Grupo I - 7 dias - quadro de reparação tecidual aguda, caracterizado por tecido necrótico e regenerativo, edema, rede de fibrina, 
grande quantidade de fibroblastos jovens e hemácias, emigração de células inflamatórias, principalmente polimorfonucleares (neutrófilos e alguns eosinófilos) (Figura 2).

2. Grupo II - 7 dias: resposta semelhante ao que se observou no Gl.

3. Grupo I - 30 dias: tecido conjuntivo frouxo, contendo fibroblastos e leucócitos, tecido de granulação reparativo do tipo mixoide, contendo neovasos e hemácias. Fibroblastos com núcleos menores e mais alongados que os observados aos sete dias e grande quantidade de células inflamatórias, com predomínio de mononucleares (linfócitos, macrófagos, plasmócitos, neutrófilos e eosinófilos). Pseudocápsula organizada e densa ao redor de toda a esfera, composta por fibroblastos maduros, poucas células inflamatórias, vasos ativos e redução do edema tecidual em relação ao observado aos sete dias. A pseudocápsula era mais espessa na região anterior.

4. Grupo II - 30 dias: as características do Gl se repetiram no Gll (Figura 3).

5. Grupo I - 90 dias: fibroblastos maduros, inflamação escassa, com predomínio de linfócitos e macrófagos, vasos sanguíneos, denotando processo inflamatório crônico, composto por tecido conjuntivo denso, organizado e maduro (Figura 4).

6. Grupo II - 90 dias: grupos Gl e Gll tiveram resposta tecidual muito semelhante.

Exame morfométrico: houve redução da espessura da pseudocápsula ao longo do experimento, com valores semelhantes estatisticamente, principalmente quando se avaliou a pseudocápsula das posições posterior e superior. Entretanto, na porção anterior e inferior, esta última, medida que coincidia com o fundo-de-saco inferior, a pseudocápsula era estatisticamente mais espessa na porção anterior no Gl aos sete dias e no Gll, aos 30 dias. Na posição inferior os grupos Gl e Gll tiveram pseudocápsula mais espessa aos sete dias, decaindo ao longo do experimento, com diferença significativa apenas no GII. A comparação dos grupos mostrou que no Gl a espessura da pseudocápsula foi maior na posição anterior aos sete dias, sem outras alterações estatísticas nos demais locais, em todos os momentos avaliados. No Gll, aos 30 dias a espessura foi maior no setor anterior e aos 90 dias a espessura foi maior na porção posterior, sem outras alterações significativas. Comparando-se a espessura da pseudocápsula de animais do Gl contra animais de Gll, só houve diferença significativa na posição posterior, quando os animais do Grupo II apresentaram espessura da pseudocápsula maior do que observado no $\mathrm{Gl}$, em especial aos sete e 90 dias. Ou seja, os animais que tiveram implantação de esferas rígidas (GII) apresentaram pseudocápsula mais espessa que os que receberam esferas gelatinosas (Quadro 1).

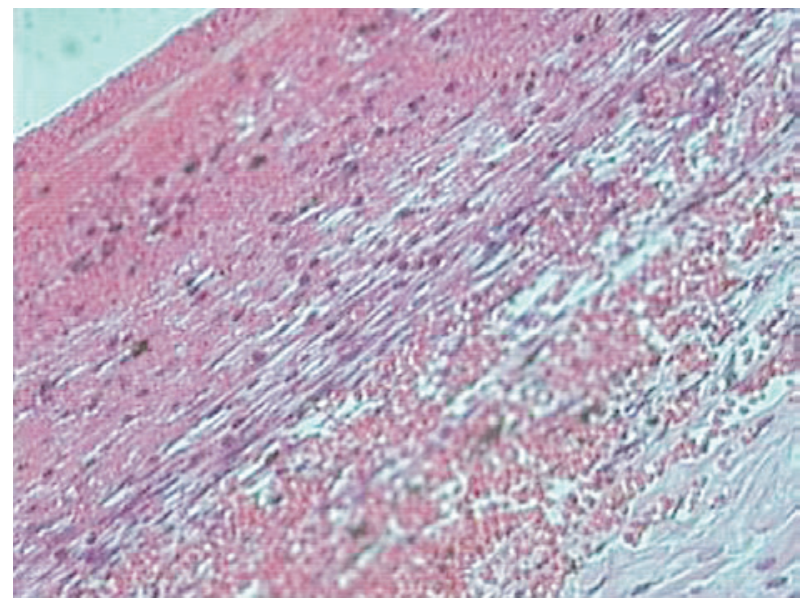

Figura 2. Fotomicrografia de animal do GI no 7ํ dia após cirurgia de evisceração. Observa-se grande quantidade de hemácias e fibroblastos jovens do tecido conjuntivo. (Hematoxilina-eosina, 40X).

\section{DISCUSSÃO}

Seguindo modelo experimental estabelecido para estudo de biomateriais para reconstrução da cavidade anoftálmica(10-12), foram utilizadas esferas de silicone gelatinosas de 10 mm de diâmetro, comparadas com esferas de silicone rígidas, em cavidades evisceradas de coelhos. As avaliações clínicas diárias, a ultrassonografia 15 dias após o início do experimento e as avaliações morfológicas e morfométricas foram as variáveis estudadas, a fim de conhecer a evolução da resposta tecidual ao material implantado, com possibilidade de avaliar as fases aguda e crônica da reparação cicatricial.

A evolução clínica mostrou que não houve interferência dos procedimentos realizados com a homeostase dos animais, já que os coelhos se desenvolveram normalmente. O único óbito observado decorreu de fenômenos gastrointestinais.

A cavidade anoftálmica após a colocação da esfera mostrou em ambos os grupos escassa reação inflamatória, com secreção em pequena quantidade, fenômeno semelhante ao que se observa clinicamente em humanos que utilizam próteses orbitárias.

Ocorreram três extrusões (total de 10\%), todas elas próximas ao ato cirúrgico, que poderiam estar relacionadas com problemas de técnica operatória, como defeitos nas suturas ou contaminação no

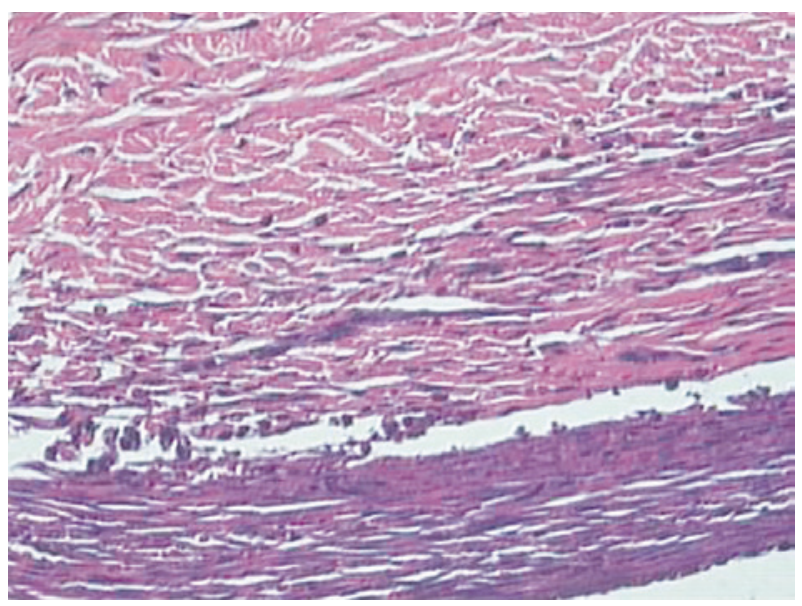

Figura 3. Fotomicrografia de animal de Gllno $30^{\circ}$ dia após cirurgia de evisceração. Formação da pseudocápsula, composta por acúmulo de fibroblastos e células inflamatórias. (Hematoxilina-eosina, 40X).

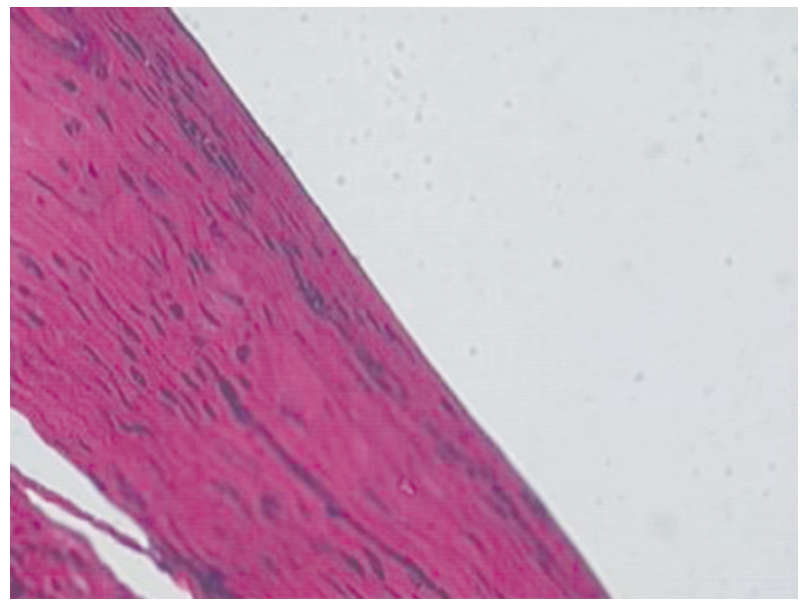

Figura 4. Fotomicrografia de animal de GI no 90 ㅁia após cirurgia de evisceração. Infiltração por células mononucleares e proliferação de fibroblastos e pequenos vasos, mostrando inflamação crônica. (Hematoxilina-eosina, 40X). 


\begin{tabular}{|c|c|c|c|c|c|}
\hline $\begin{array}{l}\text { Tipo de } \\
\text { esfera }\end{array}$ & $\begin{array}{c}\text { Dias de } \\
\text { sacrifício }\end{array}$ & Anterior & Posterior & Superior & Inferior \\
\hline \multirow[t]{3}{*}{ Gl } & 7 & $43,8 \pm 27,5(b B \alpha)$ & $34,6 \pm 15,5(\alpha A \alpha)$ & $44,3 \pm 24,3(\alpha A \alpha)$ & $40,8 \pm 26,2(\alpha A \alpha)$ \\
\hline & 30 & $18,3 \pm 7,1(\alpha A \alpha)$ & $16,2 \pm 7,8(\alpha A \alpha)$ & $42,6 \pm 27,5(\alpha A \alpha)$ & $24,3 \pm 16,3(\alpha A \alpha)$ \\
\hline & 90 & $25,0 \pm 14,2(a b A \alpha)$ & $14,6 \pm 3,5(\alpha A \alpha)$ & $36,7 \pm 15,0(\alpha A \alpha)$ & $20,9 \pm 6,6(\alpha A \alpha)$ \\
\hline \multirow[t]{3}{*}{ Gll } & 7 & $17,4 \pm 4,5(a b A \alpha)$ & $50,4 \pm 30,5(\alpha A \beta)$ & $35,9 \pm 21,5(\alpha A \alpha \beta)$ & $44,1 \pm 20,3(b A \alpha \beta)$ \\
\hline & 30 & $42,3 \pm 3,0(b B \alpha)$ & $39,6 \pm 22,2(\alpha A \alpha)$ & $31,1 \pm 8,7(\alpha A \alpha)$ & $38,3 \pm 22,7(a b A \alpha)$ \\
\hline & 90 & $15,6 \pm 3,3(\alpha A \alpha)$ & $38,3 \pm 18,2(\alpha B \beta)$ & $30,3 \pm 13,7(\alpha A \alpha \beta)$ & $16,4 \pm 3,9(\alpha \mathrm{A} \alpha)$ \\
\hline
\end{tabular}

\footnotetext{
- Duas médias seguidas de uma mesma letra minúscula são semelhantes $(P>0,05)$ entre si quanto aos momentos de sacrifício, fixados o local e o momento de avaliação.

- Duas médias seguidas de uma mesma letra maiúscula são semelhantes $(P>0,05)$ entre si quanto aos tipos de materiais avaliados, fixados o momento de sacrifício e grupo.

- Duas médias seguidas de uma mesma letra grega são semelhantes ( $P>0,05)$ entre si quanto aos momentos de avaliação, fixados o tipo de material avaliado e momento de sacrifício. Síntese da análise:

$7 \neq 30$ dias $=>$ Grupo I e Posição Anterior

$30 \neq 90$ dias $=>$ Grupo $\|$ e Posição Anterior

$7 \neq 90$ dias $=>$ Grupo $\|$ e Posição Inferior

$\mathrm{G} \mid \neq \mathrm{G} \|=>30$ dias e Posição Anterior

7 dias e Posição Anterior

90 dias e Posição Posterior

Anterior $\neq$ Posterior $=>$ Grupo $\|$ e 7 dias Grupo II e 90 dias

Posterior $\neq$ Inferior $=>$ Grupo $\|$ e 90 dias
}

ato cirúrgico; as extrusões tardias resultam de contrações cicatriciais, do uso de implantes demasiado grandes; nenhuma delas depende necessariamente do tipo de implante utilizado ${ }^{(13)}$.

O fechamento da ferida cirúrgica seguiu outros estudos de cavidade anoftálmica que usaram fios inabsorvíveis ${ }^{(11,14)}$. Apesar dos fios absorvíveis também serem usados para sutura escleral em cavidades anoftálmicas ${ }^{(12,15)}$, a preferência pelo fio inabsorvível decorre da lenta cicatrização da esclera e também porque fios absorvíveis estão relacionados com inflamação exacerbada pelo próprio processo de absorção dos mesmos.

O exame ultrassonográfico é um método de observação in vivo, tecnicamente um exame fácil, não invasivo( ${ }^{(16)}$, e foi feito sem a necessidade de anestesia geral do animal.

A técnica empregada para preparo do material para exame histológico faz com que o xilol dissolva as esferas. Sendo assim, a avaliação foi feita sobre a reação tecidual observada na pseudocápsula que envolvia as esferas, local de relação direta entre a esclera e a esfera. A inclusão em resina poderia permitir o estudo da esfera. No entanto, levando em conta que este implante não tem poros, o que seria encontrado dentro da esfera seria apenas silicone e não acrescentaria nada ao estudo.

A evisceração do olho é reparada por tecido conectivo e fibrose, com contração cicatricial do tecido escleral, reduzida pela colocação de implantes. Qualquer material estranho que seja implantado em um organismo vivo, leva à formação de uma pseudocápsula, composta inicialmente por uma rede de fibrina que evolui para fibroblastos jovens, presença de células leucocitárias, hemácias e neovasos. As células inflamatórias, inicialmente leucócitos, aprisionam e degradam bactérias, corpos estranhos e os detritos de células necróticas. Mediadores químicos e radicais tóxicos são liberados e podem prolongar a inflamação e aumentar o dano tecidual. Com o passar do tempo, a resposta inflamatória aguda passa para a fase crônica, com predomínio de outras células, associadas com macrofagia, proliferação de pequenos vasos sanguíneos e tecido conectivo e os fibroblastos jovens se tornam maduros. Estas mudanças caracterizam o processo de cicatrização, com substituição do tecido lesado por tecido conjuntivo(17-19), e foram observadas ao longo do nosso período experimental, de forma semelhante a que acontece com implantação de outros materiais em cavidades anoftálmicas ${ }^{(4,11,20)}$.

O tempo final de observação escolhido para o presente estudo foi de 90 dias. No entanto, outros preferem observar por tempo mais longo, chegando-se até 180 dias ${ }^{(4,5,11)}$. Tempos maiores de observação permitem conhecer a reação tecidual tardia e estariam indicados caso a reação inflamatória ou a pseudocápsula ainda fossem muito exuberantes aos 90 dias ou sinais de processo em evolução ainda estivessem presentes.

O exame morfométrico confirmou as observações clínicas e histológicas. Feito utilizando técnicas modernas, com avaliação sistemática em quatro locais da cavidade orbitária, permitiu comparações dentro de grupos, dentro de diferentes momentos e nos diferentes locais de observação, confirmando que a pseudocápsula foi mais espessa no início do experimento, com os dois tipos de esfera, provavelmente devido aos fenômenos inflamatórios da fase aguda, quando ocorre grande exsudação de líquido e afluxo de células para o sítio cirúrgico. Com o passar do tempo, houve redução da espessura da pseudocápsula, como consequência da redução do edema, das hemácias e da quantidade de células inflamatórias no sítio de lesão, com valores significativos.

Houve tendência da pseudocápsula em ambos os grupos ser mais espessa na posição anterior e inferior, em relação à posterior e superior, principalmente nas fases iniciais da pesquisa. Provavelmente a porção anterior está mais exposta a fatores do meio externo e em contato com os fios de sutura, assim como o setor inferior, local que coincidia com o fundo-de-saco inferior que é relacionado com maior contaminação, motivos para que estas regiões tivessem mais inflamação.

Procurando-se diferenças entre os materiais, a espessura da pseudocápsula na posição posterior, considerada a posição que não sofre interferência de fatores externos, foi maior ao redor de esferas de silicone rígidas (GII) do que de esferas de silicone gelatinosas (Gl), principalmente aos sete e 90 dias de observação. Portanto, os resultados apontam que as esferas de silicone rígidas provocaram maior reação inflamatória no decorrer do experimento. 
O próximo passo será avaliar como se dá a relação da esfera gelatinosa com a prótese externa. Embora o período de 90 dias seja bastante empregado em estudos experimentais, avaliações a longo prazo também serão necessárias.

Desta forma, o presente estudo abre novas oportunidades de pesquisas, que terão como foco definir de forma incontestável se esferas de silicone gelatinosas devem substituir as de materiais rígidos para a reparação de cavidades anoftálmicas.

\section{CONCLUSÃO}

Esferas de silicone implantadas em cavidade eviscerada de coeIhos resultam em boa resposta clínica, ultrassonográfica e histológica. As esferas de silicone gelatinoso apresentaram menor reação inflamatória e pseudocápsula menos espessa que as de silicone rígido, mostrando que esferas de silicone gelatinosas podem ser úteis para a reparação de cavidades anoftálmicas.

\section{AGRADECIMENTOS}

Os autores agradecem a Prof. Dra. Noeme Souza Rocha pelo auxílio na avaliação das lâminas histológicas deste estudo e a doutoranda Michelle Omodei pelo auxílio na avaliação diária dos animais.

\section{REFERÊNCIAS}

1. den Tonkelaar I, Henkes HE, van Leersun GK. Herman Snellen (1834-1908) and Müller's 'reform-auge'. A short story of the artificial eye. Doc Ophtalmol. 1991;77(4): 349-54.

2. Migliori ME. Enucleation versus evisceration. Curr Opin Ophthalmol. 2002;13(5): 298-302.

3. Perry JD, Lewis CD, Levine M. Evisceration after complete evaluation an acceptable option. Arch Ophthalmol. 2009;127(9):1227-8; author reply 1229. Comment on Arch Ophthalmol. 2009;127(2):141-5.

4. Ferraz LCB, Schellini SA, Wludarski SL, Padovani CR. Implantes de polietileno gel e poroso em cavidade anoftálmica de coelhos. Arq Bras Oftalmol. 2006;69(3):305-8.

5. Brandão SM. Análise da biocompatibilidade de cones de biovidro e biovitrocerâmico em cavidade eviscerada de coelho [dissertação]. Botucatu: Faculdade de Medicina da Universidade Estadual Paulista "Júlio de Mesquita Filho"; 2010.

6. Xavier AP, Schellini SA, Aragon FF, Padovani CR, Taga EM. Short-term evaluation of non-absorbable microgranular hydroxyapatite infiltration in the guinea pig subepidermal abdominal region. Braz J Med Biol Res. 2002;35(1):69-73.

7. Schellini SA, Zimmerman GP, Hoyama E, Pellizon CH, Padovani CR, Selva D. Polyethylene gel in the subcutaneous tissue of rats: histopathologic and systemic evaluation. Orbit. 2008;27(3):153-6.

8. LaTrenta GS. Breast augmentation. In: Rees TD, LaTrenta GS, editors. Aesthetic plastic surgery. 2nd ed. Philadelphia: Saunders; c1994. p. 1003-49.

9. Johnson RA, Wichern DW. Applied multivariate statistical analysis. $5^{\text {th }}$ ed. New Jersey: Prentice-Hall; c2002. 767 p.

10. Jordan DR, Mawn LA, Brownstein S, McEachren TM, Gilberg SM, Hill V, et al. The bioceramic orbital implant: a new generation of porous implants. Ophthal Plast Reconstr Surg. 2000;16(5):347-55.

11. Schellini SA, Marques ME, Padovani CR, Taga EM, Rossa R. Comparison of synthetic hydroxyapatite and porous polyethylene implants in eviscerated rabbit eyes. Ophthal Plast Reconstr Surg. 2003;19(2):136-9.

12. Jordan DR, Brownstein S, Dorey M, Yuen VH, Gilberg S. Fibrovascularization of porous polyethylene (Medpor) orbital implant in a rabbit model. Ophthal Plast Reconstr Surg. 2004:20(2):136-43.

13. Schellini SA, Ichida FK, Padovani CR. Extrusão dos implantes em portadores de cavidade anoftálmica. Arq Bras Oftalmol. 2007;70(5):752-5.

14. Shiratori CA Schellini SA, Marques MEA, Padovani CR, Padovani CRP. Avaliação da gordura orbitária de coelhos após enucleação e evisceração. Arq Bras Oftalmol. 2005; 68(5):631-3.

15. Thakker MM, Fay AM, Pieroth L, Rubin PA. Fibrovascular ingrowth into hydroxyapatite and porous polyethylene orbital implants wrapped with acellular dermis. Ophthal Plast Reconstr Surg. 2004;20(5):368-73.

16. Yamamoto ES, Hoyama E, Schellini SA, Padovani CR. Avaliação ultrassonográfica do implante orbitário em cavidade anoftálmica. Rev Bras Oftalmol. 2001;60(9):637-42.

17. Cotran RS; Kumar V; Robbins SL; Shoen FJ. Robbins pathologic basis of disease. Philadelphia: W.B. Saunders Company, 1994. Cap. 3, p. 45-83.

18. Kierszenbaum AL. Histologia e biologia celular: uma introdução à patologia. Rio de Janeiro: Elsevier; 2004. p.103-243.

19. Kumar V, Abbas AK, Fausto N. Robbins \& Cotran patologia: bases patológicas das doenças. 7a ed. Rio de Janeiro: Elsevier; 2005. p. 49-53.

20. Brito MK. Análise da biocompatibilidade da esfera de quitosana porosa em cavidade eviscerada de coelho. Estudo comparativo com polietileno poroso [dissertação]. Botucatu: Faculdade de Medicina da Universidade Estadual Paulista "Júlio de Mesquita Filho"; 2008.

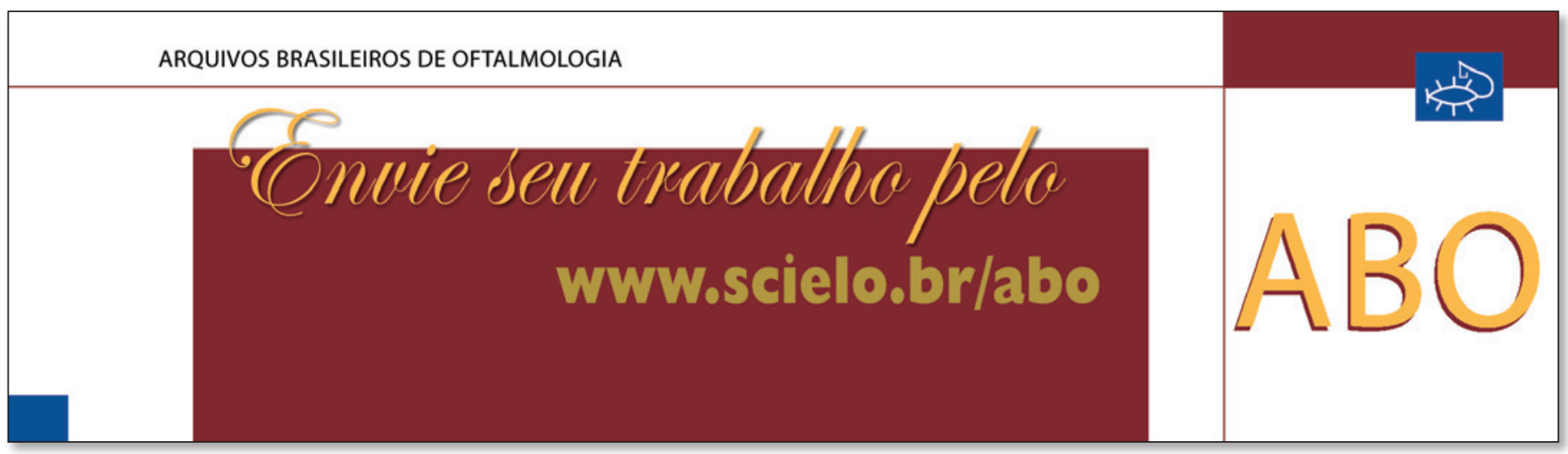

